\title{
Multiple sclerosis incidence rate in southern Iran: a Bayesian epidemiological study
}

\author{
Naeimehossadat Asmarian ${ }^{1 \dagger}$, Zahra Sharafi ${ }^{2,3^{*}+}$, Amin Mousavi ${ }^{4}$, Reis Jacques ${ }^{5}$, Ibon Tamayo ${ }^{6}$, Marie-Abèle Bind ${ }^{6}$,
} Marzie Abutorabi-zarchi ${ }^{7}$, Mohammad Javad Moradian ${ }^{8}$ and Sadegh Izadi ${ }^{9}$

\begin{abstract}
Background: Multiple Sclerosis (MS) remains to be a public health challenge, due to its unknown biological mechanisms and clinical impacts on young people. The prevalence of this disease in Iran is reported to be 5.30 to 74.28 per 100,000-person. Because of high prevalence of this disease in Fars province, the purpose of this study was to assess the spatial pattern of MS incidence rate by modeling both the associations $s$ of spatial dependence between neighboring regions and risk factors in a Bayesian Poisson model, which can lead to the improvement of health resource allocation decisions.

Method: Data from 5468 patients diagnosed with MS were collected, according to the McDonald's criteria. New cases of MS were reported by the MS Society of Fars province from 1991 until 2016. The association between the percentage of people with low vitamin D intake, smoking, abnormal BMI and alcohol consumption in addition to spatial structure in a Bayesian spatio-temporal hierarchical model were used to determine the relative risk and trend of MS incidence rate in 29 counties of Fars province.

Results: County-level crude incidence rates ranged from 0.22 to 11.31 cases per 100,000-person population. The highest relative risk was estimated at 1.80 in the county of Shiraz, the capital of Fars province, while the lowest relative risk was estimated at 0.11 in Zarindasht county in southern of Fars. The percentages of vitamin D supplementation intake and smoking were significantly associated with the incidence rate of MS. The results showed that $1 \%$ increase in vitamin D supplementation intake is associated with $2 \%$ decrease in the risk of MS and $1 \%$ increase in smoking is associated with $16 \%$ increase in the risk of MS.
\end{abstract}

\footnotetext{
* Correspondence: Zahra10926@gmail.com

${ }^{\dagger}$ Naeimehossadat Asmarian and Zahra Sharafi contributed equally to this work.

${ }^{2}$ Health Promotion Research Center, Zahedan University of Medical Sciences, Zahedan, Iran

${ }^{3}$ Department of Epidemiology \& Biostatistics, School of Health, Zahedan University of Medical Sciences, Zahedan, Iran

Full list of author information is available at the end of the article
}

C C The Author(s). 2021 Open Access This article is licensed under a Creative Commons Attribution 4.0 International License, which permits use, sharing, adaptation, distribution and reproduction in any medium or format, as long as you give appropriate credit to the original author(s) and the source, provide a link to the Creative Commons licence, and indicate if changes were made. The images or other third party material in this article are included in the article's Creative Commons licence, unless indicated otherwise in a credit line to the material. If material is not included in the article's Creative Commons licence and your intended use is not permitted by statutory regulation or exceeds the permitted use, you will need to obtain permission directly from the copyright holder. To view a copy of this licence, visit http://creativecommons.org/licenses/by/4.0/ The Creative Commons Public Domain Dedication waiver (http://creativecommons.org/publicdomain/zero/1.0/) applies to the data made available in this article, unless otherwise stated in a credit line to the data. 
Conclusion: Bayesian spatio-temporal analysis of MS incidence rate revealed that the trend in the south and south east of Fars province is less steep than the mean trend of this disease. The lower incidence rate was associated with a higher percentage of vitamin D supplementation intake and a lower percentage of smoking. Previous studies have also shown that smoking and low vitamin D, among all covariates or risk factors, might be associated with high incidence of MS.

Keywords: Bayesian spatio-temporal model, Multiple sclerosis, Incidence rate

\section{Background}

Multiple Sclerosis (MS) is an autoimmune disorder in which the central nervous system myelin is attacked. It results in focal lesions and clinical symptoms $[1,2]$. The disease is classified into four different courses: a) Relapsing- Remitting (RR) MS, the most common type, b) Secondary Progressive (SP); c) Primary Progressive (PP) MS, accounts for only $10 \%$ of the cases; and d) Progressive Relapsing (PR) MS [3]. Worldwide, more than 2.3 million individuals are affected by these different types of MS per year [4-6]. The distribution of MS increases with increasing distance from the Equator with some exceptions. Canada, Norway, and Sweden have some of the highest prevalence rates of MS in the world, reported in 2013. However, there are exceptions; some countries farther away from the equator, such as Russia, have low prevalence. On the other hand, other countries which are closer to the equator, for instance Australia, show a high prevalence of the disease [5, 6]. Epidemiological studies based on the geographical regions shows that the prevalence of the disease ranged from 5.30 to 74.28 per 100,000 individuals in Iran, which is not evenly distributed across different regions [7]. Fars province, with 72.10/100,000 (116.50 in females and 28.30 in males) prevalence rate in 2013, is one of the provinces with high risk of this disease. The mean annual incidence rate was 5.2/100,000 from 2002 until 2012 in this province [8].

Environmental factors and lifestyle approaches including vitamin $\mathrm{D}$ deficiency, obesity, alcohol consumption, and cigarette smoking have been identified as risk factors. Both low vitamin D levels and cigarette smoking are the strongest risk factors $[5,6,9,10]$. Although many studies have investigated the epidemiology of MS and the association effect of different genetic, environmental factors and lifestyle on this disease [2, 6, 11-21], to the best of our knowledge, no study has assessed the associations effects of covariates, space and time on incidence rate of MS in Fars province through Bayesian spatiotemporal model.

This study models the incidence rate of MS in Fars province in southern Iran over a 26-year-period from 1991 to 2016 for identifying geographic patterns. We simultaneously investigate the association of some covariates such as vitamin D supplementation intake, smoking, body-mass index (BMI) and alcohol consumption on the number of news cases of MS in 29 counties of Fars province, using Bayesian spatiotemporal model.

\section{Methods \\ Study area}

Fars province is located in the southwest region of Iran (Fig. 1 left) and covers $120,608 \mathrm{~km}^{2}$ of land. The province is subdivided into 29 counties and has 4.80 million inhabitants (51\% males) according to 2016 census report by the Statistical Center of Iran (SCI) [22]. According to census, Fars population in 1996 was $3,817,036$ $(1,927,415$ males and $1,889,621$ females), in 2006 was $4,336,878(2,204,852$ males and 2,132,026 females), and in 2016 it reached 4,851,274 (2,461,251 males and $2,390,023$ females). The population at risk in each year was obtained from SCI. To average out, the population at risk (i.e. scaled 1/100,000) in 2006 for the 29 counties is shown in Fig. 1 (right). As shown in the Fig. 1 (right), Shiraz has the highest population at risk.

\section{Data}

This is a historical and retrospective cohort study which was carried out in MS Society of Fars province from 1991 until 2016. This center is the only MS registry center in Fars province, so the information of almost all MS patients is available in its database. All MS patients who fulfilled the McDonald's criteria [23] from 1991 to 2016 were included in this study. Suspicious cases were referred to the MS committee of Shiraz University of Medical Sciences (SUMS) and were again reevaluated by three expert neurologists to confirm their diagnosis. For all cases, the time at first symptom is defined as time of MS onset. We excluded all patients from other neighboring provinces that were registered in this longitudinal database. In each county, risk factors included: percentage of people that took vitamin D supplements such as calcium vitamin $\mathrm{D}$, cod liver oil and multivitamin not on a regular basis, percentage of smoking population (smoker started smoking before MS onset), percentage of people with abnormal BMI and alcohol consumption (alcohol consumption before MS onset) in the population within the period of 1991-2016. Information about 


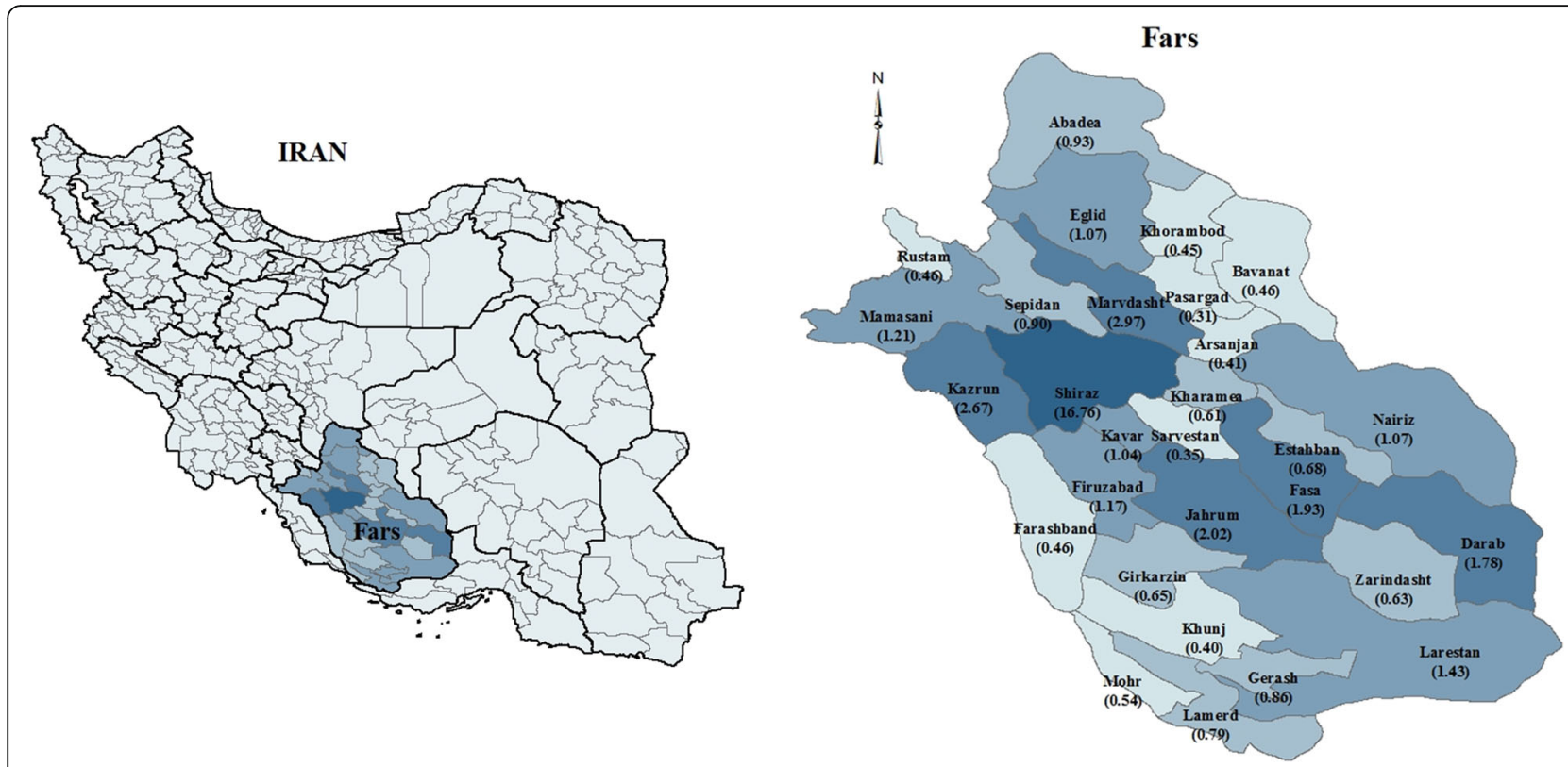

Fig. 1 geographical location of Fars province in Iran country (left) and counties located in Fars province (right) (created using ArcGIS Desktop: Release 10.1, https://www.esri.com/en-us/arcgis/about-arcgis/overview)

risk factors, based on sampling method proportionate to the population in each county, were obtained from the STEPS reports of Non-communicable diseases (National Institute of Health Research of Iran, https://nihr.tums.ac. ir/) and report annual risk factors in each county in Fars province which are available in Shiraz University of Medical Sciences database.

\section{Statistical analysis}

In this study, the geographical variations of MS incidence rate in 29 counties were analyzed. Standardized Incidence Rate (SIR) was calculated for each county, using the direct method. The observed number of new MS cases in a geographic unit (county) was assumed to follow a Poisson distribution. Furthermore, we considered vitamin D intake, smoking status, BMI, and alcohol consumption as contributing factors. For the assessment of spatial effects and the risk factors on relative risks data were analyzed. Bayesian spatio-temporal model, presented by Bernardinelli et al. [24], was used to identify the temporal pattern of MS incidence rate. Bernardinelli et al. [24] extended the BYM model formula, suggested by Besag, York and Mollie [BYM] [25], with a temporal $[24,25]$. The spatio-temporal trend model can be written as

$$
\eta_{i t}=\alpha+x_{i t}^{T} \gamma+v_{i}+u_{i}+\left(\beta+\delta_{i}\right) * t
$$

The BYM and spatio-temporal models are the most popular full Bayesian models that were explained in many references in detail (see Lawson, A [26]. and
Blangiardo M, Cameletti M.) [27]. In these models, the intercept $(\boldsymbol{\alpha})$ and fixed effects (rick factors) $(\gamma)$ were assumed to follow an improper uniform and normal distribution with zero mean and a small variance as prior, respectively. The unstructured effects $\left(\boldsymbol{v}_{\boldsymbol{i}}\right)$, the structured spatial $\left(u_{i}\right)$ effects and interaction between space and time $\left(\delta_{i}\right)$ are random effects and the precision parameters, controlling the amount of variability for the random effects, were assumed to follow a gamma distribution $(0.50,0.0005)$, as suggested by Bernardinelli et al. [24].

Where incidence, prevalence and confidence intervals (Confidence Interval for a Poisson distribution) were calculated using STATA Software [28]. The spatiotemporal model was coded in the OpenBUGS version 3.2.3 [29] for estimating parameters (see codes of spatial and spatio-temporal models-page 129- in Lawson et.al [30] and ArcGIS 10.1 [31] was used to display results on maps. We ran two chains with 1000 samples as burn-in and 10,000 samples as iteration. Convergence for the chains were confirmed by auto-correlations, trace and densities plots [32].

\section{Results}

We identified 5468 new MS cases (4344 (79\%) women and $1124(21 \%)$ men) in Fars province from 1991 to 2016. A total of 3664 patients $(67 \%)$ were from the city of Shiraz, the capital of Fars province.

Table 1 shows the number of new MS cases in each year, incidence rate per 100,000 populations, age, and the number of females and males in each year in Fars province during 26 years. The highest and lowest 
Table 1 Incidence of MS per 100,000 persons in the county levels of Fars province in the south of Iran from 1991 to 2016

\begin{tabular}{|c|c|c|c|c|c|c|}
\hline \multirow[t]{2}{*}{ Year } & \multirow[t]{2}{*}{ No. of cases } & \multirow[t]{2}{*}{ Incidence rate $(95 \% \mathrm{Cl})$} & \multicolumn{2}{|c|}{ Age at onset (y) } & \multirow[t]{2}{*}{ No. of cases Female/male } & \multirow[t]{2}{*}{ F/M ratio } \\
\hline & & & Mean \pm SD & Min-max & & \\
\hline 1991 & 22 & $0.61(0.40,0.93)$ & $28.45 \pm 8.11$ & $(10-45)$ & $13 / 9$ & 1.44 \\
\hline 1992 & 8 & $0.22(0.11,0.44)$ & $30.30 \pm 8.08$ & $(22-44)$ & $6 / 2$ & 3.00 \\
\hline 1993 & 32 & $0.86(0.61,1.22)$ & $25.12 \pm 8.73$ & $(8-44)$ & $21 / 11$ & 1.91 \\
\hline 1994 & 28 & $0.75(0.52,1.08)$ & $26.89 \pm 8.25$ & $(11-43)$ & $18 / 10$ & 1.80 \\
\hline 1995 & 35 & $0.92(0.66,1.28)$ & $27.32 \pm 8.09$ & $(16-46)$ & $29 / 6$ & 4.83 \\
\hline 1996 & 35 & $0.91(0.65,1.27)$ & $27.43 \pm 8.28$ & $(12-46)$ & $31 / 4$ & 7.75 \\
\hline 1997 & 26 & $0.67(0.45,0.98)$ & $25.24 \pm 5.89$ & $(14-40)$ & $21 / 5$ & 4.20 \\
\hline 1998 & 48 & $1.22(0.92,1.61)$ & $31.51 \pm 12.8$ & $(13-77)$ & $39 / 9$ & 4.33 \\
\hline 1999 & 77 & $1.93(1.54,2.41)$ & $28.21 \pm 8.43$ & $(14-48)$ & $59 / 18$ & 3.28 \\
\hline 2000 & 77 & $1.90(1.52,2.38)$ & $29.44 \pm 8.77$ & $(9-48)$ & $62 / 15$ & 4.13 \\
\hline 2001 & 91 & $2.22(1.81,2.73)$ & $28.01 \pm 8.50$ & $(8-55)$ & $77 / 14$ & 5.50 \\
\hline 2002 & 104 & $2.51(2.07,3.04)$ & $28.20 \pm 8.42$ & $(14-53)$ & $86 / 18$ & 4.78 \\
\hline 2003 & 119 & $2.83(2.37,3.39)$ & $29.09 \pm 9.03$ & $(11-56)$ & $106 / 13$ & 8.15 \\
\hline 2004 & 133 & $3.13(2.64,3.71)$ & $28.58 \pm 8.46$ & $(10-59)$ & $101 / 32$ & 3.16 \\
\hline 2005 & 199 & $4.63(4.03,5.32)$ & $28.57 \pm 8.06$ & $(13-53)$ & $169 / 30$ & 5.63 \\
\hline 2006 & 199 & $4.57(3.98,5.26)$ & $28.82 \pm 8.62$ & $(12-59)$ & $170 / 29$ & 5.86 \\
\hline 2007 & 228 & $5.18(4.55,5.90)$ & $31.23 \pm 10.80$ & $(7-86)$ & $186 / 42$ & 4.43 \\
\hline 2008 & 279 & $6.27(5.58,7.05)$ & $30.09 \pm 8.98$ & $(9-55)$ & $221 / 58$ & 3.81 \\
\hline 2009 & 288 & $6.40(5.70,7.18)$ & $30.47 \pm 9.01$ & $(10-56)$ & $237 / 51$ & 4.65 \\
\hline 2010 & 391 & $8.59(7.78,9.49)$ & $29.77 \pm 8.64$ & $(8-63)$ & $323 / 68$ & 4.75 \\
\hline 2011 & 438 & $9.52(8.67,10.46)$ & $31.49 \pm 9.45$ & $(5-69)$ & $366 / 72$ & 5.08 \\
\hline 2012 & 488 & $10.49(9.60,11.47)$ & $30.26 \pm 8.84$ & $(7-64)$ & $405 / 83$ & 4.88 \\
\hline 2013 & 510 & $10.85(9.95,11.83)$ & $30.80 \pm 9.08$ & $(9-60)$ & $397 / 113$ & 3.51 \\
\hline 2014 & 537 & $11.31(10.39,12.30)$ & $32.11 \pm 9.40$ & $(11-64)$ & $432 / 105$ & 4.11 \\
\hline 2015 & 533 & $11.10(10.20,12.09)$ & $32.09 \pm 9.27$ & $(8-62)$ & $415 / 118$ & 3.52 \\
\hline 2016 & 543 & $11.20(10.29,12.18)$ & $32.43 \pm 8.82$ & $(11-62)$ & $354 / 189$ & 1.87 \\
\hline
\end{tabular}

incidence rates were observed in 2014 as $11.31(95 \%$ Confidence Interval (CI) $(10.39,12.30)$ per 100,000) and 1992 as $0.22(95 \%$ CI $(0.11,0.44)$ per 100,000$)$. In addition, the highest and lowest age means were observed in $2014(32.11 \pm 9.40)$ and 1993 (25.12 \pm 8.73$)$. The highest and lowest female/male ratios were observed in 2006 (5.86) and 1991(1.44).
Age-specific prevalence rates of MS are shown in Table 2. The highest and lowest prevalence rates belonged to 20-30 (362.10 (95\% CI, (347.31, 377.28) per $100,000)$ and $>60$ (4.60, 95\% CI, $(2.61,7.59)$ per 100,000) age group. A statistically significant difference was determined between the prevalence of MS among men and women $(P<0.0001)$, except age group $>60$. Highest and

Table 2 Age-specific prevalence rates of MS in the county (per 100,000 persons) of Fars province in the south of Iran from 1991 to 2016

\begin{tabular}{llllll}
\hline Age group & No. of cases & Prevalence & No. of cases Female/male & F/M ratio & $P$-value $\mathbf{F}$ to $\mathbf{M}$ \\
\hline$<20$ & 689 & $97.61(90.40-105.19)$ & $567 / 122$ & 4.65 & $<0.0001$ \\
$20-30$ & 2261 & $362.10(347.31-377.28)$ & $1797 / 464$ & 3.87 & $<0.0001$ \\
$30-40$ & 1629 & $233.02(221.77-244.60)$ & $1301 / 328$ & 3.97 & $<0.0001$ \\
$40-50$ & 742 & $167.10(155.89-179.60)$ & $565 / 177$ & 3.19 & $<0.0001$ \\
$50-60$ & 132 & $40.01(33.40-47.32)$ & $105 / 27$ & 3.89 & $<0.0001$ \\
$>60$ & 15 & $4.60(2.61-7.59)$ & $9 / 6$ & 1.50 & 0.6056 \\
\hline
\end{tabular}


lowest values of MS Female/male ratio were observed in age groups $<20(4.65)$ and $>60(1.50)$.

We generated maps of geographical variations of MS incidence across the 29 counties of Fars province with classic SIR (Fig. 2A), BYM model (Fig. 2B) spatiotemporal trend model (Fig. 2C), and posterior estimate value of $\delta_{i}$ (Fig. 2D). $\delta_{i}$ shows the difference between the global trend of incidence rate and the area-specific trend of incidence rate $\left(\delta_{i}<0\right.$, shows that this trend is less steep than the mean trend, while $\delta_{i}>0$ shows that the areaspecific trend of incidence rate is steeper than the mean trend). The maps should be interpreted by considering that different shades are proportional to the incidence rate value. In other words, darker areas have the higher incidence rate. The averages of SIRs and relative risks were 0.52 and 0.43 , respectively. As can be seen in Fig. 2 (A and B), Shiraz is at higher risk than other counties. Shiraz had the highest SIR and relative risk for MS with

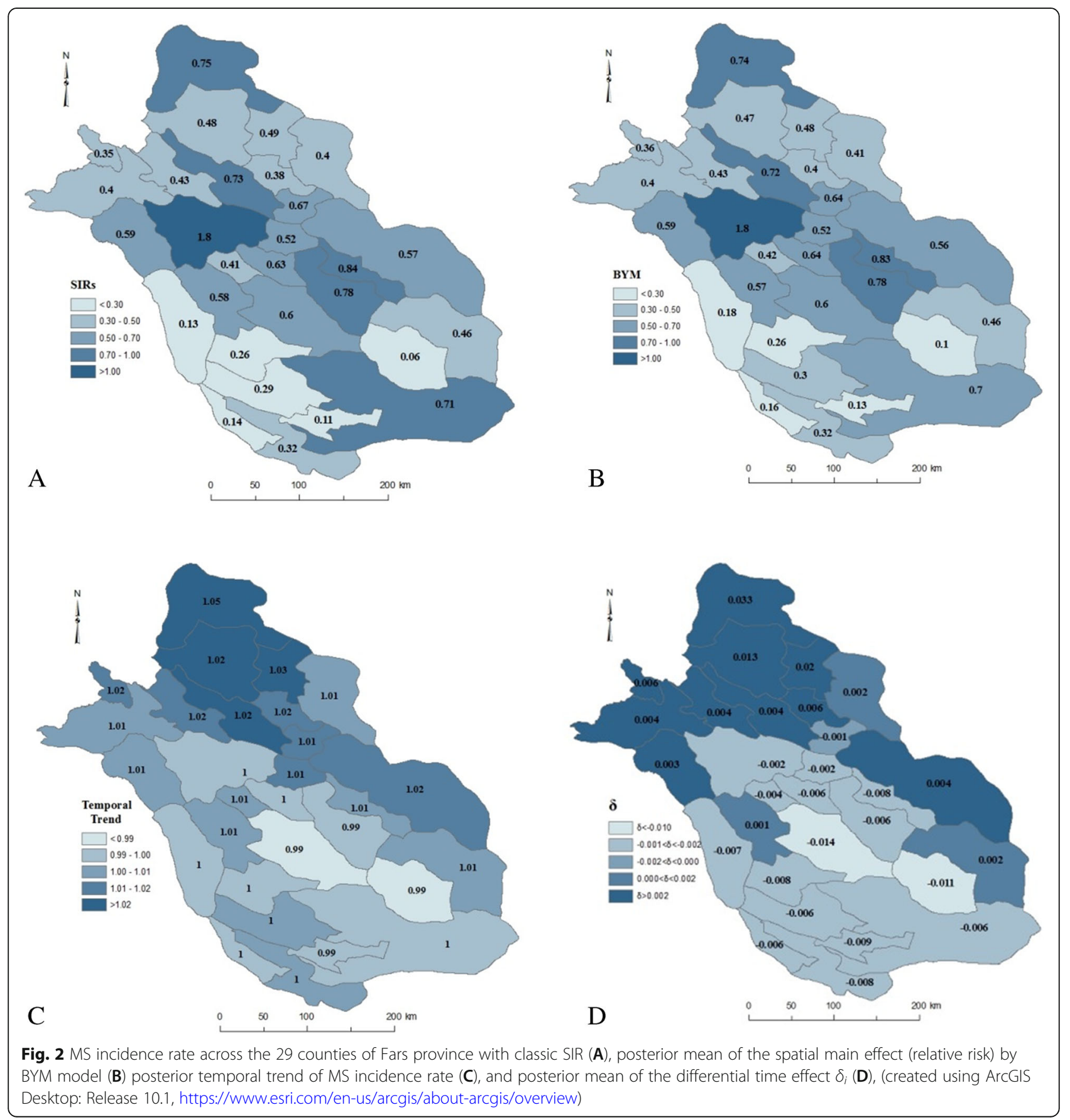


values of 1.80 and 1.80 (standard deviation $=0.03$ ), respectively. Zarindasht county in southeast of Fars province had the lowest SIR and relative risk with values of 0.06 and 0.11 (standard deviation $=0.03$ ), respectively. Figure $2 \mathrm{C}$ shows the temporal trend of the incidence rate across different regions of Fars province during the period of 1991-2016. The estimated value of time coefficient in this model was 0.0075 . The exponential corresponding to the coefficient of time is equal to 1.007 for each successive year. This finding shows that although there is an increasing trend of incidence in Fars, it is very uniform. Figure 2D shows the change of temporal patterns of MS incidence rate. Darker areas show that the trend is steeper for those counties compared with the global trend and brighter areas show that the trend is less steep than the global trend.

Another important point that can be inferred from Fig. $2 \mathrm{C}$ is the steady increase of incidence rate of relative risk over time in the northern regions of Fars province. Figure $2 \mathrm{~B}$ depicts the average over a period of 26 years, showing higher overall incidence rates in the central regions of Fars. On the other hand, Fig. 2C incorporates relative changes over this time period, showing a geographical shift of the incidence rate from the central regions to the northern regions of the province.

Table 3 is a summary of the statistics related to different covariates used in BYM model. The estimated fixed effects show that the percentages of vitamin D intake is negatively associated with MS incidence while the percentage of people with smoking status is positively associated with MS incidence. It was found that $1 \%$ increase in vitamin D supplementation intake is associated with $2 \%$ decrease in the risk of MS incidence whereas $1 \%$ increase in smoking is associated with $16 \%$ increase in the risk of MS incidence.

\section{Discussion and conclusion}

This study spatially evaluated the MS incidence distribution in Fars province, using Bayesian model. Spatial description of the disease is a useful tool for evaluating the incidence rate data and could lead to further public health investigations and interventions [33]. As far as we know, this is the first study that has estimated the spatio- temporal incidence rate of MS in Fars province. This study also investigates the association of vitamin D supplementation intake, smoking, BMI, and alcohol consumption with MS incidence rate as well as spatial dependence between the neighboring regions. The findings suggest that further studies are warranted in order to confirm the allocations of health resource across different region.

In the current study, the average of Female/male ratio was 4.25 and women had higher risk than men. Among the age groups, the highest prevalence belonged to range $20-30$ (362.10 per 100,000 -person), and then $30-40$ years old (233.00 per 100,000-person). Our results are similar to Sahraian et al.'s study [34] on 8000 cases of MS in 2010. They reported that the most cases of MS were in the age range of 20-39 years old and Iranian women have higher risk of MS. The results of spatio-temporal model describe the low incidence rate of MS in south and southeast of Fars province. Zarindasht county, located in south with a rather hot and dry climate and high temperature, had the lowest incidence rate. This result is in line with previous studies that showed maintaining adequate levels of vitamin $D$ (as one of the environmental factors) has a protective effect. It also results in lower risk of developing autoimmune diseases including MS [35-37]. The results of BYM model (without time effect) in this study showed that larger counties, located in the center of Fars province, especially Shiraz and Abadeh in northeast, had high MS incidence rates. This is in concordance with previous studies which showed MS to be more common among urban dwellers than rural ones [38]. There is no clear explanation as to why, but Dehghani et al. [39] introduced urbanization as a major risk factor in incidence rate of MS in Iran. In addition, Sahraian et al. [40] indicated that the impact of air pollution, unhealthy lifestyle, exposure to industrial solvents, low exposure to sunlight, infectious agents and smoking have increased incidence rate of MS among urban dwellers.

Our results showed that the percentage of vitamin $\mathrm{D}$ supplementation intake and smoking are associated with the risk of MS incidence which is in line with previous studies that had suggested that maintaining adequate

Table 3 Summary statistics: posterior mean, posterior standard deviation (SD) and posterior 95\% credibility interval for the fixed effects of BYM models in MS incidence

\begin{tabular}{llll}
\hline Covariate & Coefficient (SD) & Exp (coefficient) & 95\% credible Interval \\
\hline \% of vitamin D supplementation intake & $-0.02(0.01)$ & 0.98 & $(-.02,-0.01)^{*}$ \\
\% of smoking & $0.15(0.06)$ & 1.16 & $(0.03,0.24)^{*}$ \\
\% of normal BMI & $0.02(0.02)$ & 1.02 & $(-0.02,0.02)$ \\
\% of Alcohol consumption & $1.01(0.78)$ & 2.75 & $(-0.51,2.58)$ \\
\hline
\end{tabular}


levels of vitamin D could have a protective effect by lowering the risk of developing autoimmune diseases including MS [35-37]. When a person has MS, his or her immune system attacks the coating that protects nerve cells. Research suggests a significant positive association of vitamin D on the immune system [35-37, 41]. Smoking as a risk factor can influence the course of MS [16, 42,43 . Both the duration and intensity of smoking can contribute independently to the increased risk of MS [44]. Consistent studies on MS patients and healthy controls have provided evidence that both active and passive smoking can result in an increased risk of MS and disease progression. Studies have shown that the risk of MS associated with HLA genotypes is increased by smoking status [42, 45].

According to several studies, obesity is one of the potential risk factors of MS. The growing world-wide obesity epidemic has multiple deleterious effects on public health and has also been associated with an increased risk of MS [46]. Increased obesity leads to lower levels of 25-hydroxyvitamin D which in turn predisposes to MS [47]. The association between obesity and MS is similar among men and women, and the observed trend of higher BMI resulted in a higher risk of developing MS [48]. However, in our study BMI had no association with the incidence of MS.

Although the impact of alcohol, which might directly suppress various immune responses, on the risk of developing MS has been investigated in different studies, the results were inconsistent. In some studies, researchers found no association between alcohol intake and the risk of MS [49]. But some studies showed a potential dependency between alcohol consumption and the incidence of MS [10].

\section{Conclusion}

Bayesian spatio-temporal analysis of MS incidence rate revealed that the trend in the south and south east of Fars province is less steep than the mean trend of this disease. The lower incidence rate was associated with a higher percentage of vitamin D supplementation intake and a lower percentage of smoking. Previous studies have also shown that smoking and low vitamin D, among all covariates or risk factors, might be associated with high incidence of MS.

Our study was a long-term study in an almost uniform population but it had some limitations which should be taken into consideration in future studies. The major limitation in such studies is the incomplete registration of information due to lack of diagnosis facilities and access to neurologist, especially in rural areas. However, the various models in disease mapping, such as Bayesian hierarchical models, for smoothing disease rates and solving this problem have been suggested. Bayesian hierarchical models try to improve the estimates of log risk by using neighbor regions information in a spatial structured component as well as region variation in an unstructured component. Despite these models, government supports for the complete recording of information could increase the accuracy of the estimates.

Another limitation is related to risk factors. We needed covariates in each area during study for spatiotemporal modeling. However, some covariates such as climate, sunlight, air pollution industrial solvents and so on, were not available per year between 1991 and 2016; hence, we had the information of four covariates during this period. We are hoping, by improving the quality of data registration in Iran in recent years, to investigate environmental causes by statistical analysis very soon.

\section{Abbreviations}

MS: Multiple Sclerosis; RR: Relapsing- Remitting; SP: Secondary Progressive; PP: Primary Progressive; PR: Progressive Relapsing; BMI: Body-Mass Index; SCl: Statistical Center of Iran; SUMS: Shiraz University of Medical Sciences; STEPS: .; SIR: Standardized Incidence Rate; BYM: Besag, York and Mollie; Cl: Confidence Interval; SD: Standard Deviation

\section{Acknowledgments}

This study was approved by the Ethics Committee of Shiraz University of Medical Sciences (no. \#94-10638).

\section{Authors' contributions}

NSA and ZSH: designed the study, performed the statistical analyses, interpretation and wrote the manuscript, AM: interpret statistical analysis and wrote the manuscript. RJ, IT, MAB, MA and MJ M: were consulted on the design of the study and reviewed the draft. SI: collected information of all patients during 26 years, recorded the time of onset of disease and reviewed the draft. All authors read and approved the final manuscript.

\section{Funding}

This research received no specific grant from any funding agency in the public, commercial or not-for-profit sectors.

\section{Availability of data and materials}

The datasets are available from the corresponding author upon reasonable request.

\section{Declarations}

Ethics approval and consent to participate

All procedures performed in this study utilizing secondary data analysis were approved by the Ethics committee and in accordance with the ethical standards of the Shiraz University of Medical Sciences, IRAN. Written consent was originally obtained by the MS Society of Fars province from participants.

\section{Consent for publication}

Not applicable.

\section{Competing interests}

The authors declare that they have no competing interests.

\section{Author details}

${ }^{1}$ Anesthesiology and Critical Care Research Center, Shiraz University of Medical Sciences, Shiraz, Iran. ${ }^{2}$ Health Promotion Research Center, Zahedan University of Medical Sciences, Zahedan, Iran. ${ }^{3}$ Department of Epidemiology \& Biostatistics, School of Health, Zahedan University of Medical Sciences, Zahedan, Iran. ${ }^{4}$ Department of Educational Psychology and Special Education, College of Education, University of Saskatchewan, Saskatoon, Canada. ${ }^{5}$ Service de Neurologie, Centre Hospitalier Universitaire, Hôpital de Hautepierre, 1, avenue Molière, 67200 Strasbourg, France. ${ }^{6}$ Department of Statistics, Faculty of Arts and Science, Harvard University, Cambridge, MA, 
USA. ${ }^{7}$ Department of neurology, Faculty of Medicine, Shahid Sadoughi University of Medical Sciences, Yazd, IR, Iran. ${ }^{8}$ Trauma Research Center, Shahid Rajaee (Emtiaz) Trauma Hospital, Shiraz University of Medical Sciences, Shiraz, Iran. ${ }^{9}$ Clinical Neurology Research Center, Shiraz University of Medical Sciences, Shiraz, Iran.

Received: 7 June 2020 Accepted: 3 August 2021

Published online: 10 August 2021

\section{References}

1. Gourraud PA, Harbo HF, Hauser SL, Baranzini SE. The genetics of multiple sclerosis: an up-to-date review. Immunol Rev. 2012;248(1):87-103. https:// doi.org/10.1111/j.1600-065X.2012.01134.x.

2. Dyment DA, Ebers GC, Sadovnick AD. Genetics of multiple sclerosis. Lance Neurol. 2004;3(2):104-10. https://doi.org/10.1016/S1474-4422(03)00663-X.

3. Lublin FD, Reingold SC, Cohen JA, Cutter GR, Sørensen PS, Thompson AJ, et al. Defining the clinical course of multiple sclerosis: the 2013 revisions. Neurology. 2014;83(3):278-86. https://doi.org/10.1212/WNL. 0000000000000560 .

4. Milo R, Kahana E. Multiple sclerosis: geoepidemiology, genetics and the environment. Autoimmun Rev. 2010;9(5):A387-94. https://doi.org/10.1016/j.a utrev.2009.11.010.

5. A visual look at new worldwide multiple sclerosis prevalence data [https:// www.vitamindcouncil.org/a-visual-look-at-new-worldwide-multiple-sclerosisprevalence-data/].

6. Thompson AJ, Baranzini SE, Geurts J, Hemmer B, Ciccarelli O. Multiple sclerosis. Lancet. 2018;391(10130):1622-36. https://doi.org/10.1016/S01406736(18)30481-1.

7. Etemadifar M, Sajjadi S, Nasr Z, Firoozeei TS, Abtahi SH, Akbari M, et al. Epidemiology of multiple sclerosis in Iran: a systematic review. Eur Neurol. 2013;70(5-6):356-63. https://doi.org/10.1159/000355140.

8. Izadi S, Nikseresht AR, Poursadeghfard M, Borhanihaghighi A, Heydari ST. Prevalence and incidence of multiple sclerosis in Fars Province, southern Iran. Iran J Med Sci. 2015;40(5):390-5.

9. Pekmezovic T, Drulovic J, Milenkovic M, Jarebinski M, Stojsavljevic N Mesaros S, et al. Lifestyle factors and multiple sclerosis: a case-control study in Belgrade. Neuroepidemiology. 2006;27(4):212-6. https://doi.org/10.1159/ 000096853.

10. Hedström A, Hillert J, Olsson T, Alfredsson L. Alcohol as a modifiable lifestyle factor affecting multiple sclerosis risk. JAMA Neurol. 2014;71(3):300-5. https://doi.org/10.1001/jamaneurol.2013.5858.

11. Ascherio A, Munger KL. Environmental risk factors for multiple sclerosis. Part I: the role of infection. Ann Neurol. 2007;61(4):288-99. https://doi.org/10.1 002/ana.21117.

12. Browne P, Chandraratna D, Angood C, Tremlett H, Baker C, Taylor BV, et al. Atlas of multiple sclerosis 2013: a growing global problem with widespread inequity. Neurology. 2014;83(11):1022-4. https://doi.org/10.1212/WNL. 0000000000000768 .

13. Dumas M, Jauberteau-Marchan MO. The protective role of Langerhans' cells and sunlight in multiple sclerosis. Med Hypotheses. 2000;55(6):517-20. https://doi.org/10.1054/mehy.2000.1109.

14. Ebers GC. Environmental factors and multiple sclerosis. Lancet Neurol. 2008; 7(3):268-77. https://doi.org/10.1016/S1474-4422(08)70042-5.

15. Giovannoni G, Ebers G. Multiple sclerosis: the environment and causation. Curr Opin Neurol. 2007;20(3):261-8. https://doi.org/10.1097/WCO.0b013e32 $815610 \mathrm{c} 2$

16. Hedstrom AK, Hillert J, Olsson T, Alfredsson L. Smoking and multiple sclerosis susceptibility. Eur J Epidemiol. 2013;28(11):867-74. https://doi.org/1 0.1007/s10654-013-9853-4.

17. Hoseinzadeh E, Taha P, Wei C, Godini H, Ashraf GM, Taghavi M, et al. The impact of air pollutants, UV exposure and geographic location on vitamin D deficiency. Food Chem Toxicol. 2018;113:241-54. https://doi.org/10.1016/j. fct.2018.01.052.

18. Koch-Henriksen N, Stenager E, Laursen B. The use of epidemiological multiple sclerosis registers in research: the Danish MS registry. Acta Neurol Scand Suppl. 2012;195:7-12.

19. Kurtzke JF. Epidemiologic evidence for multiple sclerosis as an infection. Clin Microbiol Rev. 1993:6(4):382-427. https://doi.org/10.1128/CMR.6.4.382

20. Orton SM, Herrera BM, Yee IM, Valdar W, Ramagopalan SV, Sadovnick AD, et al. Sex ratio of multiple sclerosis in Canada: a longitudinal study. Lancet Neurol. 2006;5(11):932-6. https://doi.org/10.1016/S1474-4422(06)70581-6.
21. Pivot D, Debouverie M, Grzebyk M, Brassat D, Clanet M, Clavelou P, et al. Geographical heterogeneity of multiple sclerosis prevalence in France. PLoS One. 2016;11(12):e0167556. https://doi.org/10.1371/journal.pone.0167556.

22. Statistical Center of Iran. Iran National Census, Tehran, Statistical Center of Iran 2016. https://amar.org.ir/english.

23. Polman $\mathrm{CH}$, Reingold SC, Banwell B, Clanet M, Cohen JA, Filippi M, et al. Diagnostic criteria for multiple sclerosis: 2010 revisions to the McDonald criteria. Ann Neurol. 2011;69(2):292-302. https://doi.org/10.1 002/ana.22366.

24. Bernardinelli L, Clayton D, Pascutto C, Montomoli C, Ghislandi M, Songini M. Bayesian analysis of space - time variation in disease risk. Stat Med. 1995; 14(21-22):2433-43. https://doi.org/10.1002/sim.4780142112.

25. Besag J, York J, Mollié A. Bayesian image restoration, with two applications in spatial statistics. Ann Inst Stat Math. 1991;43(1):1-20. https://doi.org/10.1 007/BF00116466.

26. Lawson A: Bayesian disease mapping. Hierarchical Modeling in Spatial Epidemiology.; 2009.

27. Blangiardo M, Cameletti M, Baio G, Rue H. Spatial and spatio-tempora models with R-INLA. Spatial Spatiotemporal Epidemiol. 2013;4:33-49.

28. Moghaddam VK, Sarmadi M, Tatari M, Najafi F, Esmaeili A, Hadei M. Epidemiology of multiple sclerosis in Torbat-e Heydarieh (northeast of Iran) during 1982-2016. Multiple Sclerosis Related Disorders. 2018;24:184-9. https://doi.org/10.1016/j.msard.2018.07.008.

29. Spiegelhalter D, Thomas A, Best N, Lunn D. OpenBUGS; 2014.

30. Lawson $A B$, Browne WJ, CL. VR: disease mapping with WinBUGS and MLwiN: John Wiley \& Sons Itd; 2003. https://doi.org/10.1002/0470856068.

31. ESRI: ArcGIS Desktop: Release 10. Redlands: Environmental Systems Research Institute. 2011.

32. Sharafi Z, Asmarian N, Hoorang S, Mousavi A. Bayesian spatio-temporal analysis of stomach cancer incidence in Iran, 2003-2010. Stochastic Environ Res Risk Assess. 2018;32(10):2943-50.

33. Ebrahimipour M, Budke CM, Najjari M, Cassini R, Asmarian N. Bayesian spatial analysis of the surgical incidence rate of human cystic echinococcosis in North-Eastern Iran. Acta Trop. 2016:163:80-6. https://doi. org/10.1016/j.actatropica.2016.08.003.

34. Sahraian MA, Khorramnia S, Ebrahim MM, Moinfar Z, Lotfi J, Pakdaman H. Multiple sclerosis in Iran: a demographic study of 8,000 patients and changes over time. Eur Neurol. 2010;64(6):331-6. https://doi.org/10.1159/000321649.

35. Alharbi FM. Update in vitamin D and multiple sclerosis. Neurosciences. 2015 20(4):329-35. https://doi.org/10.17712/nsj.2015.4.20150357.

36. Fitzgerald KC, Munger KL, Kochert K, Arnason BG, Comi G, Cook S, et al. Association of Vitamin D Levels with Multiple Sclerosis Activity and Progression in patients receiving interferon Beta-1b. JAMA Neurol. 2015; 72(12):1458-65. https://doi.org/10.1001/jamaneurol.2015.2742.

37. Wawrzyniak S, Mikołajewska E, Kuczko-Piekarska E, Niezgodzińska-Maciejek A, Goch A. Association of vitamin D status and clinical and radiological outcomes in a treated MS population in Poland. Brain Behavior. 2017;7(2): e00609. https://doi.org/10.1002/brb3.609.

38. Boyle C. Multiple Sclerosis-The Facts You Need. 2005. By Paul O'Connor. Published by Key Porter Books. 155 pages. Price C \$19.95. Can J Neurol Sci. 2006:33(1):120.

39. Dehghani R, Sahraian MA, Yunesian M, Hadeii M, Gilasi HR, KazemiMoghaddam V. Reply to urbanization theory for growing trend of multiple sclerosis letter. Iran J Public Health. 2017:46(11):1601-2.

40. Sahraian MA, Sahebkar M, Dehghani R, Derakhshan-Jazari M, KazamiMoghaddam V, Kouchaki E. Multiple sclerosis-a disease on a dramatically rising trend in Iran: review of possible reasons. Iran J Neurol. 2017;16(1):34-40.

41. D'Hooghe M B, Haentjens P, Nagels G, Garmyn M, De Keyser J: Sunlight exposure and sun sensitivity associated with disability progression in multiple sclerosis. Multiple sclerosis (Houndmills, Basingstoke, England) 2012, 18(4):451-459.

42. Hedstrom AK, Sundqvist E, Baarnhielm M, Nordin N, Hillert J, Kockum I, et al. Smoking and two human leukocyte antigen genes interact to increase the risk for multiple sclerosis. Brain. 2011;134(Pt 3):653-64. https://doi.org/10.1 093/brain/awq371

43. Hernan MA, Olek MJ, Ascherio A. Cigarette smoking and incidence of multiple sclerosis. Am J Epidemiol. 2001;154(1):69-74. https://doi.org/10.1 093/aje/154.1.69.

44. Wingerchuk DM. Smoking: effects on multiple sclerosis susceptibility and disease progression. Ther Adv Neurol Disord. 2012;5(1):13-22. https://doi. org/10.1177/1756285611425694. 
45. Hedstrom AK, Bomfim IL, Barcellos LF, Briggs F, Schaefer C, Kockum I, et al. Interaction between passive smoking and two HLA genes with regard to multiple sclerosis risk. Int J Epidemiol. 2014;43(6):1791-8. https://doi.org/10.1 093/ije/dyu195.

46. Munger KL, Bentzen J, Laursen B, Stenager E, Koch-Henriksen N, Sorensen TI, Baker JL: Childhood body mass index and multiple sclerosis risk: a longterm cohort study. Multiple sclerosis (Houndmills, Basingstoke, England) 2013, 19(10):1323-1329.

47. Harroud A, Morris JA, Manousaki D, Forgetta V, Mitchell R, Smith GD, Sawcer S, Richards JB. Distinct Effects of Obesity and Vitamin D on Risk of Multiple Sclerosis: A Mendelian Randomization Study (P2. 351).

48. Hedstrom AK, Olsson T, Alfredsson L: High body mass index before age 20 is associated with increased risk for multiple sclerosis in both men and women. Multiple sclerosis (Houndmills, Basingstoke, England) 2012, 18(9): 1334-1336.

49. Carle A, Pedersen IB, Knudsen N, Perrild H, Ovesen L, Rasmussen LB, et al. Moderate alcohol consumption may protect against overt autoimmune hypothyroidism: a population-based case-control study. Eur J Endocrinol. 2012;167(4):483-90. https://doi.org/10.1530/EJE-12-0356.

\section{Publisher's Note}

Springer Nature remains neutral with regard to jurisdictional claims in published maps and institutional affiliations.

Ready to submit your research? Choose BMC and benefit from:

- fast, convenient online submission

- thorough peer review by experienced researchers in your field

- rapid publication on acceptance

- support for research data, including large and complex data types

- gold Open Access which fosters wider collaboration and increased citations

- maximum visibility for your research: over $100 \mathrm{M}$ website views per year

At BMC, research is always in progress.

Learn more biomedcentral.com/submissions 